\title{
Amnestic Mild Cognitive Impairment and Early Alzheimer's Disease in an Asian Memory Clinic - Evidence for a Clinical Spectrum
}

\author{
M. Chan L. Tay M.S. Chong \\ Cognition and Memory Disorders Service, Department of Geriatric Medicine, Tan Tock Seng \\ Hospital, Singapore
}

\section{Key Words}

Alzheimer's disease $\cdot$ Clinical dementia rating $\cdot$ Disease spectrum $\cdot$ Mild cognitive impairment

\begin{abstract}
Objectives: To determine if mild cognitive impairment $(\mathrm{MCl})$ represents a continuum of cognitive and functional deficits. Methods: Clinical data of 164 subjects with no dementia (ND, $n=$ 52), uncertain dementia ( $n=69)$, and mild probable Alzheimer's disease $(A D, n=43)$ were reviewed. Uncertain dementia patients were classified as pre-MCI $(n=11)$, early amnestic $\mathrm{MCl}$ (e-aMCl, $\mathrm{n}=15)$ and late amnestic $\mathrm{MCl}(\mathrm{l}-\mathrm{aMCl}, \mathrm{n}=15)$. Cognitive assessments [Chinese MiniMental State Examination (CMMSE) and a validated neuropsychological battery], functional assessments (Lawton's scale for instrumental activities of daily living) and neuroimaging (ischemic lesions and medial temporal lobe atrophy) were reviewed. Results: $\mathrm{ND}$, aMCl and mild AD subjects demonstrated a significant trend for worsening performance for all cognitive and functional measures (ANOVA, $\mathrm{p}<0.05$ ). Pre-MCl subjects performed significantly better than aMCl subjects in all verbal memory domains $(p<0.001)$, while I-aMCI had worse functional performance $(p=0.007)$, a trend towards greater depressive symptoms $(p=0.05)$ and higher medial temporal lobe atrophy scores $(p=0.06)$. I-aMCl subjects were more likely than either pre$\mathrm{MCl}$ or e-aMCl to progress to dementia over a mean follow-up period of 2.5 years (46.7 vs. 9.1 and $20.0 \%$, respectively). Conclusions: Clinical delineation of aMCl allows the differentiation of those likely to progress for better correlation to biomarker development.
\end{abstract}

Copyright ๑ 2011 S. Karger AG, Basel 


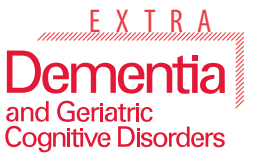

\begin{tabular}{l|l}
\hline Dement Geriatr Cogn Disord Extra 2011;1:113-123 \\
\hline DOI: 10.1159/000327519 & $\begin{array}{l}\text { @ 2011 S. Karger AG, Basel } \\
\text { www.karger.com/dee }\end{array}$ \\
\hline Published online: April 27, 2011 & \\
\hline
\end{tabular}

Chan et al.: Disease Spectrum of Amnestic MCl

\section{Introduction}

The pre-dementia at-risk state of mild cognitive impairment (MCI) is a heterogeneous entity which requires better characterization. This important transitional continuum differs from the normal cognitive state by the presence of objective cognitive impairment, but there is insufficient decline in functional status to fulfill the diagnosis of dementia [1]. Previously, subtypes of MCI based on the pattern of neuropsychological impairment have been proposed, where such distinction may mark incipient forms of different dementias [2]. With the advent of disease-modifying treatments for Alzheimer's disease (AD), the amnestic subtype of MCI (aMCI) in particular has received much attention as a possible precursor to this commonest of dementia states [3]. While such a classification may aid in etiological evaluation, it still cannot address the heterogeneity of cognitive decline observed in the spectrum of MCI subjects, or its associated impact on the latency of conversion to dementia, which was alluded to in an earlier report [4].

Additionally, the study of MCI has yielded various challenging questions. Standardized screening instruments and neuropsychological scales for definitive diagnosis of the general MCI cohort are not agreed upon [5]. Difficulties remain in defining the boundaries between normal aging and MCI, or MCI and mild dementia, as the distinction depends on the degree of functional impairment and its mode of measurement [6]. Studies examining the conversion of MCI to dementia have not accurately identified a subset which has a higher predilection for AD pathology, although multi-domain aMCI have been suggested [7]. Finally, therapeutic trials with cholinesterase inhibitors conducted on criterion-defined MCI subjects have also not shown any clear benefits in delaying cognitive deterioration or the onset of dementia [8-10].

Despite the heterogeneity observed, the pathological validity of aMCI has been supported by conversion rates to dementia of $>60 \%$ at a 2-year follow-up [11]. More accurate characterization of aMCI subjects will allow research to focus on those subjects who are most at risk of conversion to $\mathrm{AD}$ [12] and who would best stand to gain from early therapeutic interventions. It is important to realize that there is a window of opportunity for identifying subjects at a phase when pathology has already begun, but clinical diagnosis of AD is not yet achievable.

In our current study, we retrospectively examined the clinical data of subjects attending a memory clinic with the following aims: (i) to characterize patients with subjective cognitive complaints in order to discern distinctive clinical subgroups within the entity of MCI using the global staging instrument of the Clinical Dementia Rating (CDR) scale [13]; (ii) to evaluate the performances of clinically defined aMCI subjects upon cognitive screening testing, and neuropsychological and functional assessments, and (iii) to determine whether such a clinical classification system is supported by initial data on dementia conversion. We hypothesized that aMCI is a heterogeneous construct encompassing subjects with variable degrees of impairment, and there exists a spectrum of cognitive and functional deficits spanning from normal cognition to early dementia.

\section{Patients and Methods}

\section{Setting and Participants}

We reviewed all clinical information routinely captured within the memory clinic database for subjects with memory complaints but no dementia (ND), aMCI, and mild AD presenting for the first time to the Cognition and Memory Disorder Service of the Tan Tock Seng Hospital in Singapore, from the period of January 2007 to December 2008. Data were eligible for inclusion if the subject was 55 years or older; had a diagnosis of ND, pre-MCI, 
aMCI (see below), or mild probable AD and completed standardized clinical and neuropsychological evaluation. We excluded subjects with early dementia due to other etiologies and subjects with moderate- or advanced-stage dementia as indicated by a global CDR rating $\geq 2$. Subsequent information regarding conversion to dementia was reviewed at an arbitrary cutoff date set at the end of June 2010 (this gives an approximate follow-up of 2.5 years for the majority of subjects). Conduct of the study was approved by the institutional review board.

\section{Clinical Assessment}

All patients underwent detailed clinical evaluation including comprehensive cognitive history taking from the patient and a reliable collateral source, and physical examination. Relevant laboratory investigations and neuroimaging were also performed to exclude potentially reversible causes of cognitive impairment [14]. Patients were administered the Chinese Mini-Mental Status Examination (CMMSE) for mental state screening. The CMMSE had been locally validated, and modifications made to suit the cultural context of Singapore had been described previously. This includes omitting the question on season; the two questions on patient's town and county were combined into a single question yielding a total score of 28 instead of 30, and a cutoff score adjusted for severity of 20 for dementia [15]. We employed the Cornell Scale for Depression in Dementia (CSDD) for mood evaluation as a prior local comparative study indicated better diagnostic properties for this instrument compared to the Geriatric Depression Scale. While scores ranged from 0 to 38 , a value $\geq 6$ would suggest possible depression in the local setting $[16,17]$. The functional staging tool of CDR, again validated locally, was scored by a clinician after initial assessment [18].

Information obtained from a reliable informant was used to complete the Lawton and Brody's scales for instrumental activities of daily living (iADL) [19]. The scale comprises assessment of eight common daily activities: using telephone, shopping, meal preparation, housekeeping, laundry, use of transportation, self-administration of drugs, and handling of finances. The total score spans the range from 0 (total dependence) to 23 (total independence) [20].

\section{Neuropsychological Battery}

Our neuropsychological assessment battery was modeled according to the Consortium to Establish a Registry for Alzheimer's Disease psychometric instruments and had been locally validated with education adjustment [21]. The battery consists of the following items:

(1) Word list memory task: immediate recall, delayed recall and recognition memory, all of which ascertain different aspects of verbal memory.

(2) Verbal fluency (animal naming), which appraises semantic language and executive functioning.

(3) Modified Boston Naming Test, which assesses language skills.

(4) Block design, object assembly subtest of the Wechsler Adult Intelligence Scale-Revised and constructional praxis, all of which evaluate visuospatial abilities.

\section{Neuroimaging}

All neuroimaging studies (computed tomography or magnetic resonance imaging) were performed in the same center; they were reviewed for the presence of medial temporal lobe atrophy (MTA), white matter lesions and infarcts by a single rater blinded to the clinical status of the patient. Coronal slices of MRI studies parallel to the brainstem axis and perpendicular to the hippocampal axis were reviewed and an MTA score of 0 (no atrophy) to 4 (severe atrophy) was assigned based on the visual estimation of the volume of the medial temporal lobe [22]. The greater of either hemispheric score was then taken as the overall MTA score. An age-related scale rating white matter changes [23] was used for the grading of white matter lesions. Five different regions (frontal, parieto-occipital, temporal, infraten- 
torial, and basal ganglia) were rated in the right and left hemispheres on a 4-point scale. The global white matter score was then derived from the summation of the individual scores (range 0-30). Information on the presence or absence of infarcts (as a categorical variable) was obtained from the report of a neuroradiologist who reviewed the scan.

\section{Subject Classification}

The clinical diagnosis is assigned via a multi-disciplinary approach with physician, cognition nurse clinician and psychologist inputs. Subjects classified as ND were those individuals who presented to the Memory Clinic with cognitive complaints, but who after clinical evaluation, including neuropsychological assessment, were found to lack subjective and objective evidence for dementia, or did not satisfy the criteria for inclusion (i.e. subjective memory complaints only but no MCI). Conversely, patients diagnosed with mild AD were those who met criteria for probable AD as defined by the National Institute of Neurological and Communicative Disorders and Stroke-Alzheimer's Disease and Related Disorders Association [24]. Additionally, they would have a global CDR score of either 0.5 or 1 , indicating the mild nature of their dementia.

Subjects with a possible diagnosis of MCI were further discussed in a separate consensus meeting involving geriatricians running the Memory Clinic, with nurse clinician, psychologist and neurologist input to verify the diagnosis and to further determine its subtype according to the revised criteria proposed by Petersen et al. [25]. Thus, MCI subjects are operationally defined as individuals with (1) subjective memory complaints, (2) presence of objective cognitive impairment (neuropsychological domain testing noted to be $>1.0 \mathrm{SD}$ below education-adjusted means obtained from earlier normative studies) [21], (3) preserved overall general function, and (4) absence of clinical dementia as defined by global CDR $<1$ and failure to meet DSM-IV criteria for dementia (Diagnostic and Statistical Manual, edition 4). We then selected the group of subjects classified as aMCI based on their impaired performance in the delayed word list recall task for analysis. We used the arbitrary cutoff of $>1.0$ $\mathrm{SD}$ as determinant of impairment in psychometric domains as this was noted to have greater predictive power for the development of dementia in a previous population study [26].

To further explore the spectrum of pathology in aMCI, our study cohort comprised early (e-aMCI) and late aMCI (l-aMCI) according to their scores obtained for the CDR sum of boxes (CDR-SB; fig. 1). Those with CDR-SB $\leq 1.5$ are classified as e-aMCI, while the rest are assigned to the l-aMCI category. We believe that such a classification based on a global assessment scale such as the CDR-SB can delineate unique subtypes for valid comparison of baseline features. In addition, we also included a small group of patients with significant subjective as well as clinician's impression of memory complaints but who did not display impairment on standard neuropsychological testing to satisfy the inclusion criteria of MCI (i.e. global $\mathrm{CDR}=0.5$, but no domains $>1.0 \mathrm{SD}$ below adjusted norms obtained from a prior validation study). They were classified as pre-MCI for the purpose of this study. We further reviewed the data on progression for these subjects with regard to their cognitive status (unchanged, deteriorated or conversion to dementia).

\section{Statistical Analysis}

Analysis was performed with SPSS for Windows (version 16.0; SPSS, Inc., Chicago, Ill., USA). In comparing psychological performances, $\mathrm{z}$-scores were computed for all the neuropsychological test results based on education-adjusted norms obtained from a prior validation study in the local population [21]. One-factor ANOVAs with post hoc Bonferroni comparisons were performed to analyze the mean differences between groups for continuous variables, while comparisons for proportions were performed using the $\chi^{2}$ test. The level of statistical significance was set at 0.05 . 
Fig. 1. MCI subject classification.

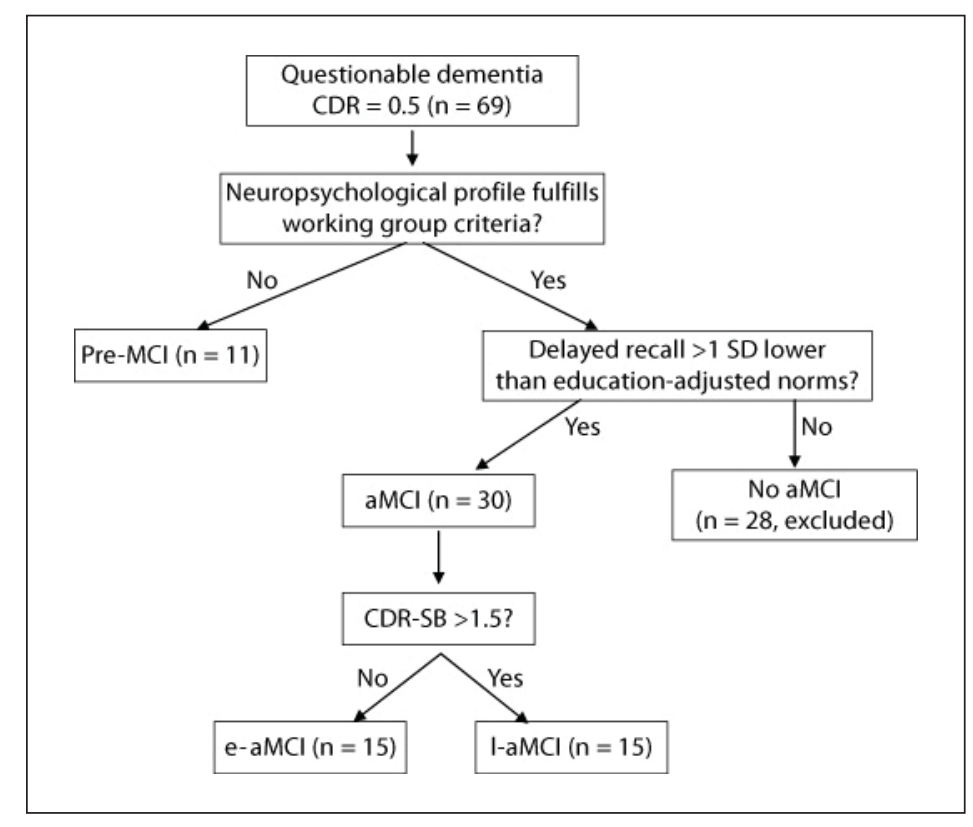

\section{Results}

\section{Baseline Demographics}

Of the 581 records available during the defined study period, 164 subjects with ND ( $\mathrm{n}=$ $52)$, questionable dementia status $(n=69)$ and mild probable $A D(n=43)$ were considered for study inclusion. We subsequently excluded 28 subjects classified as non-aMCI (fig. 1), leaving a final analytical sample of 136 subjects. Of these, 11 subjects were deemed to have pre-MCI. The remaining 125 subjects with ND, aMCI and mild AD comprise predominantly Chinese subjects $(n=113,90.4 \%)$, with a preponderance of females $(n=76,60.8 \%)$. The mean age of the subjects was $71.6 \pm 9.4$ years, with ND subjects being significantly younger than aMCI and those with early $\mathrm{AD}$ (mean age of $\mathrm{ND}=64.7 \pm 9.2$ years, vs. $74.5 \pm 6.2$ and $76.6 \pm 6.7$ years in aMCI and mild AD groups, respectively; ANOVA, $\mathrm{p}<0.001$ ). However, there was no significant difference in terms of their years of education or duration of symptoms (table 1). The mean follow-up period for the entire group was $2.5 \pm 0.6$ years.

\section{Neuropsychological and Functional Profiles}

CMMSE scores were noted to decline progressively from the categories of ND, aMCI and mild $\mathrm{AD}$ (mean scores $=25.50 \pm 2.89,21.97 \pm 4.03$ and 20.21 \pm 3.96 , respectively; ANOVA, $\mathrm{p}<0.001$ ). Not unexpectedly, the three clinical groups also demonstrated a spectrum of worsening neuropsychological test performances, achieving statistical significance across all cognitive domains upon ANOVA testing (table 2). There were significant differences upon comparison between ND versus aMCI in terms of immediate memory, recognition memory, delayed memory (post hoc Bonferroni testing, all $\mathrm{p}<0.001)$, category fluency $(\mathrm{p}=0.039)$, block design and object assembly (both $\mathrm{p}=0.008$ ). aMCI subjects also performed significantly better compared to those with mild AD in tests of delayed memory $(p=0.002)$, category fluency $(\mathrm{p}=0.02)$, and in the Boston Naming Test $(\mathrm{p}=0.001)$, further demonstrating the validity of such a clinical classification. The groups, however, did not demonstrate significant differences in the presence of depression as recorded by the CSDD (mean scores for $\mathrm{ND}$, aMCI and mild $\mathrm{AD}=5.47 \pm 4.96,4.76 \pm 4.76$ and $4.26 \pm 3.86$, respectively; $\mathrm{p}=0.46$ ). 
Table 1. Baseline characteristics of the subjects with ND, aMCI (e-aMCI and l-aMCI) and mild AD

\begin{tabular}{lccrc}
\hline & $\begin{array}{l}\text { ND } \\
(\mathrm{n}=52)\end{array}$ & $\begin{array}{l}\text { aMCI } \\
(\mathrm{n}=30)\end{array}$ & $\begin{array}{l}\text { Mild AD } \\
(\mathrm{n}=43)\end{array}$ & $\begin{array}{l}\text { p value } \\
\left(\text { ANOVA } / \chi^{2}\right)\end{array}$ \\
\hline Females, $\mathrm{n}(\%)$ & $30(57.7)$ & $17(56.7)$ & $29(67.4)$ & 0.54 \\
Chinese race, $\mathrm{n}(\%)$ & $49(94.2)$ & $29(96.7)$ & $35(81.4)$ & 0.23 \\
Age (mean \pm SD), years & $64.7 \pm 9.2$ & $74.5 \pm 6.2$ & $76.6 \pm 6.7$ & $<0.001$ \\
Years of education (mean \pm SD) & $8.1(4.9)$ & $6.9(5.1)$ & $6.8(4.9)$ & 0.39 \\
Duration of symptoms (mean \pm SD), years & $2.3 \pm 2.0$ & $1.9 \pm 1.8$ & $2.1 \pm 1.3$ & 0.57 \\
Mean follow-up period (mean \pm SD), years & $2.4 \pm 0.5$ & $2.8 \pm 0.8$ & $2.4 \pm 0.6$ & 0.06 \\
MTA score (mean \pm SD) & $0.7 \pm 0.9$ & $1.9 \pm 1.1$ & $1.9 \pm 0.8$ & $<0.004$ \\
Presence of lacunar infarcts, n (\%) & $12(24.5)$ & $13(44.8)$ & $3(7.5)$ & 0.02 \\
WML global score (mean $\pm \mathrm{SD})$ & $4.8 \pm 2.5$ & $5.0 \pm 3.0$ & $4.1 \pm 3.2$ & 0.38 \\
\hline
\end{tabular}

Table 2. Clinical and neuropsychological evaluation of subjects with ND, aMCI (e-aMCI and l-aMCI) and mild AD

\begin{tabular}{|c|c|c|c|c|c|c|}
\hline & \multirow{2}{*}{$\begin{array}{l}\text { ND } \\
(\mathrm{n}=52)\end{array}$} & \multirow{2}{*}{$\begin{array}{l}\mathrm{aMCI} \\
(\mathrm{n}=30)\end{array}$} & \multirow{2}{*}{$\begin{array}{l}\text { Mild AD } \\
(\mathrm{n}=43)\end{array}$} & \multicolumn{3}{|l|}{$\mathrm{p}$ value } \\
\hline & & & & $\begin{array}{l}\text { ANOVA } \\
\chi^{2} \text { test }\end{array}$ & $\begin{array}{l}\text { ND vs. } \\
\text { aMCI }\end{array}$ & $\begin{array}{l}\text { AD vs. } \\
\text { aMCI }\end{array}$ \\
\hline \multicolumn{7}{|l|}{ Cognitive and functional testing } \\
\hline CMMSE (mean \pm SD), $\mathrm{n} / 28$ & $25.50 \pm 2.89$ & $21.97 \pm 4.03$ & $20.21 \pm 3.96$ & $<0.001$ & $<0.001$ & 0.12 \\
\hline CSDD (mean $\pm S D)$ & $5.47 \pm 4.96$ & $4.76 \pm 4.76$ & $4.26 \pm 3.81$ & 0.46 & 1.00 & 1.00 \\
\hline $\begin{array}{l}\text { Total Lawton score } \\
\quad(\text { mean } \pm \text { SD), n/23 }\end{array}$ & $21.98 \pm 2.65$ & $19.00 \pm 4.20$ & $15.24 \pm 4.14$ & $<0.001$ & 0.002 & $<0.001$ \\
\hline \multicolumn{7}{|c|}{ Neuropsychological testing (z-scores) } \\
\hline Immediate memory & $0.17(1.08)$ & $-1.10(1.07)$ & $-1.67(1.11)$ & $<0.001$ & $<0.001$ & 0.09 \\
\hline Recognition memory & $0.15(1.15)$ & $-1.33(1.37)$ & $-1.86(2.13)$ & $<0.001$ & $<0.001$ & 0.50 \\
\hline Delayed memory & $0.24(0.99)$ & $-1.39(0.50)$ & $-2.07(0.72)$ & $<0.001$ & $<0.001$ & 0.002 \\
\hline Animal category & $-0.61(1.20)$ & $-0.70(1.02)$ & $-1.44(1.02)$ & $<0.001$ & 0.04 & 0.02 \\
\hline Boston Naming Test & $-0.31(1.36)$ & $-0.65(1.37)$ & $-2.13(2.06)$ & $<0.001$ & 1.00 & 0.001 \\
\hline Block design & $0.89(1.22)$ & $-0.63(0.93)$ & $-1.01(0.76)$ & $<0.001$ & 0.008 & 0.37 \\
\hline Object assembly & $-0.11(1.13)$ & $-0.88(1.19)$ & $-0.97(0.95)$ & 0.001 & 0.008 & 1.00 \\
\hline
\end{tabular}

The presence of increasing functional disability was also highlighted by the significant deterioration in the total Lawton score across the clinical spectrum (mean scores for ND, aMCI and mild $\mathrm{AD}=21.98 \pm 2.65,19.00 \pm 4.20$ and $15.24 \pm 4.14$, respectively; ANOVA, $\mathrm{p}<$ 0.001).

\section{aMCI Subtype Comparisons}

aMCI subjects were further classified as e-aMCI $(n=15)$ and 1 -aMCI $(n=15)$ based on their CDR-SB scores and compared with pre-MCI subjects $(n=11)$. There were no significant differences between the three categories of patients in terms of gender, race, age, educational attainment or duration of symptoms. There was a trend for poorer scores in CMMSE spanning the three MCI categories (pre-MCI, e-aMCI and l-aMCI mean scores $=26.09 \pm 1.38$, $23.33 \pm 3.56$ and $20.60 \pm 4.12$, respectively; ANOVA, $\mathrm{p}=0.001$; table 3 ). With regard to neuropsychological performance, there were significant trends for worsening performance 
Table 3. Clinical, functional and neuropsychological test performance of subjects with pre-MCI and aMCI

\begin{tabular}{|c|c|c|c|c|c|c|}
\hline & \multirow{2}{*}{$\begin{array}{l}\text { Pre-MCI } \\
(\mathrm{n}=11)\end{array}$} & \multirow{2}{*}{$\begin{array}{l}\text { e-aMCI } \\
(\mathrm{n}=15)\end{array}$} & \multirow{2}{*}{$\begin{array}{l}\text { l-aMCI } \\
(\mathrm{n}=15)\end{array}$} & \multicolumn{3}{|l|}{$\mathrm{p}$ value } \\
\hline & & & & ANOV & $\begin{array}{l}\text { A pre-vs. } \\
\text { e-aMCI }\end{array}$ & $\begin{array}{l}\text { e- vs. } \\
\text { l-aMCI }\end{array}$ \\
\hline \multicolumn{7}{|l|}{ Cognitive and functional testing } \\
\hline CMMSE (mean $\pm \mathrm{SD}), \mathrm{n} / 28^{\circ}$ & $26.09 \pm 1.38$ & $23.33 \pm 3.56$ & $20.60 \pm 4.12$ & 0.001 & 0.140 & 0.10 \\
\hline $\mathrm{CSDD}($ mean $\pm \mathrm{SD})$ & $2.56 \pm 3.91$ & $3.07 \pm 4.03$ & $6.57 \pm 4.96$ & 0.05 & 1.00 & 0.11 \\
\hline \multicolumn{7}{|l|}{ Total Lawton score } \\
\hline$($ mean $\pm S D), n / 23$ & $20.50 \pm 2.07$ & $20.93 \pm 2.02$ & $16.93 \pm 4.97$ & 0.007 & 1.00 & 0.009 \\
\hline MTA score (mean $\pm S D)$ & $0.67 \pm 1.03$ & $1.00 \pm 0.00$ & $2.11 \pm 1.17$ & 0.06 & 1.00 & 0.62 \\
\hline Presence of lacunar infarcts, n (\%) & $7(63.6)$ & $8(53.3)$ & $5(35.7)$ & 0.36 & & \\
\hline WML global score (mean \pm SD) & $6.55 \pm 3.08$ & $3.93 \pm 2.58$ & $6.07 \pm 1.15$ & 0.057 & 0.09 & 0.17 \\
\hline \multicolumn{7}{|l|}{ Neuropsychological testing (z-scores) } \\
\hline Immediate memory & $0.59(0.74)$ & $-1.26(0.98)$ & $-0.94(1.16)$ & $<0.001$ & $<0.001$ & 1.00 \\
\hline Recognition memory & $0.68(0.40)$ & $-1.27(1.47)$ & $-1.39(1.32)$ & $<0.001$ & $<0.001$ & 1.00 \\
\hline Delayed memory & $0.60(0.59)$ & $-1.29(0.32)$ & $-1.49(0.63)$ & $<0.001$ & $<0.001$ & 0.90 \\
\hline Animal category & $-0.16(0.73)$ & $-0.55(1.09)$ & $-0.85(0.98)$ & 0.21 & 0.93 & 1.00 \\
\hline Boston Naming Test & $0.42(0.55)$ & $-0.67(1.37)$ & $-0.64(1.42)$ & 0.06 & 0.10 & 1.00 \\
\hline Block design & $0.20(1.02)$ & $-0.70(1.20)$ & $-0.56(0.59)$ & 0.06 & 0.08 & 1.00 \\
\hline Object assembly & $-0.15(1.17)$ & $-0.99(1.26)$ & $-0.78(1.16)$ & 0.22 & 0.27 & 1.00 \\
\hline
\end{tabular}

in all three memory domains (ANOVA, $\mathrm{p}<0.001$ ), with superior performance noted in the pre-MCI group. Amongst the non-memory domains, a trend for worsening performance was noted in the category fluency, although this did not reach statistical significance (ANOVA, $\mathrm{p}=0.21$ ). While not statistically significant, l-aMCI subjects were noted to have higher depression scores than their pre-MCI and e-aMCI counterparts (mean score ANOVA, $\mathrm{p}=0.05$ ). Furthermore, l-aMCI subjects had significantly poorer performance in iADL as measured by the Lawton's scale (mean score $16.93 \pm 4.97$, vs. $20.50 \pm 2.07$ and $20.93 \pm 2.02$ in preMCI and e-aMCI, respectively, ANOVA, $\mathrm{p}=0.007$ ).

\section{Neuroimaging Findings}

$\mathrm{ND}(24.5 \%)$ and aMCI (44.8\%) subjects were more likely than $\mathrm{AD}(7.5 \%)$ to have lacunar infarcts upon neuroimaging (ANOVA, $\mathrm{p}=0.02$ ). However, there was no difference between groups in terms of the global scores for the presence of intracranial white matter leukoaraiosis (WML; ANOVA, $\mathrm{p}=0.38$ ). Further analyses of subjects with pre-MCI, e-aMCI and l-aMCI did not reveal any significant difference both in terms of presence of lacunar infarcts or intracranial WML ( $\mathrm{p}=0.36$ and $\mathrm{p}=0.06$, respectively).

The number of neuroimaging studies for MTA analyses was limited, with only 41 out of a possible 136 subjects having suitable imaging (coronal sections of the hippocampus were only available on selected MRI studies). Mean MTA scores were significantly lower for $\mathrm{ND}$ subjects than those with aMCI and $\mathrm{AD}(0.7 \pm 0.9,1.9 \pm 1.1$ and $1.9 \pm 0.8$, respectively; $\mathrm{p}=0.04)$. A similar trend of increasing MTA score (greater atrophy) was noted for subjects with pre-aMCI, e-aMCI and $\mathrm{l}-\mathrm{aMCI}(0.7 \pm 1.0,1.0 \pm 0.0$ and $2.1 \pm 1.2$, respectively; $\mathrm{p}=0.06)$.

\section{Limited Conversion Data}

Over the follow-up period, 11 of the $41 \mathrm{MCI}$ subjects were diagnosed with dementia. The majority of patients received a diagnosis of $\mathrm{AD}(\mathrm{n}=7,63.6 \%)$, with vascular dementia being 


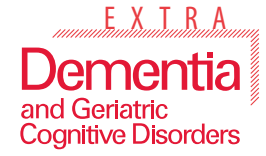

\begin{tabular}{l}
\hline \begin{tabular}{l}
\hline Dement Geriatr Cogn Disord Extra 2011;1:113-123 \\
\hline DOI: 10.1159/000327519
\end{tabular} \\
\begin{tabular}{l} 
Published online: April 27, 2011 \\
www.karger.com/dee \\
\hline
\end{tabular}
\end{tabular}

Table 4. Conversion to dementia amongst MCI subtypes

\begin{tabular}{llll}
\hline & Pre-MCI $(\mathrm{n}=11)$ & e-aMCI $(\mathrm{n}=15)$ & 1 -aMCI $(\mathrm{n}=15)$ \\
\hline Conversion to dementia, $\mathrm{n}(\%)$ & $1(9.1)^{*}$ & $3(20.0)^{*}$ & $7(46.7)^{*}$ \\
\hline${ }^{*} \mathrm{p}<0.001$. & & & \\
\hline
\end{tabular}

the next most common diagnosis $(\mathrm{n}=4,36.3 \%)$. A significant trend for greater likelihood of conversion for subjects classified as pre-MCI $(\mathrm{n}=1,9.1 \%)$, e-aMCI $(\mathrm{n}=3,20.0 \%)$ and 1 -aMCI ( $\mathrm{n}=7,46.7 \% ; \chi^{2}$ test, $\left.\mathrm{p}<0.001\right)$ was observed (table 4$)$.

\section{Discussion}

Our study was able to demonstrate the isolation of an aMCI clinical entity with neuropsychological and functional properties which are distinct and intermediary for subjects with ND and mild AD. In addition, we noted that further stratification of aMCI subjects produces a clinical subset (l-aMCI) with worse performance in most testing domains, possibly with a higher degree of MTA, being at the greatest risk of conversion to dementia in the near term. Recent studies have reported the validation of accurate radiological and cerebrospinal fluid biomarkers for AD in its incipient stages [27,28]. It is thus more crucial than ever to emphasize the accurate clinical characterization of subjects with mild amnestic complaints and correlate biological markers of disease activity with working phenotypes to ensure clinical relevance of research.

In our current study, pre-MCI subjects had greater functional impairment than those with ND (mean iADL score $20.50 \pm 2.07$ vs. $21.98 \pm 2.65$ ) despite not fulfilling neuropsychological criteria for MCI. Few studies have examined the utility of a clinical versus a neuropsychological classification of MCI subjects. Storandt et al. [29] noted that subjects with a Clinical Dementia Rating scale global score of 0.5 who do not fulfill formal neuropsychological criteria for MCI (pre-MCI) may progress to dementia, indicating that AD may be identified at an even earlier stage than MCI. Yet another study found that subjects with questionable $\mathrm{AD}(\mathrm{CDR}=0.5)$ were more likely to convert to dementia if their CDR-SB score was $>1.5$ [30]. In contrast, a recent large population study on MCI noted that classification of subjects with CDR 0.5 may be influenced by demographic, cognitive and clinical factors, with lower rates of conversion to dementia than those fulfilling neuropsychological criteria for MCI [31]. The utility of clinical stratification of subjects with subtle memory complaints therefore requires further clarification in subsequent prospective studies.

The current study also highlighted the spectrum of functional abilities amongst this group of subjects with mild cognitive deficits, ranging from minimal deficits in the ND group to significant impairment in l-aMCI and mild AD subjects. Additionally, our study noted that functional impairment bears little correlation with the burden of intracranial ischemic lesions (both lacunar infarcts and WML), which were similar between the categories of MCI patients. Previous reports have alluded to the importance of functional assessment in the evaluation of subjects with MCI who had been shown to perform poorer than age- and sex-matched cognitively unimpaired controls in iADL [32]. Mariani et al. [33] also noted that both memory deficits and executive dysfunction may account for the restriction in iADL [33]. As functional independence is the key to patient autonomy and quality of life, 
Wadley et al. [34] have suggested that the preservation of function be used as a meaningful outcome measure for interventional efforts in MCI subjects. However, more work in larger patient groups is still required to better characterize the relationship between the degree of functional impairment and the severity of cognitive decline for this at-risk group, where burden of disease is usually mild.

While we did not detect any difference in depressive symptoms between subjects with $\mathrm{ND}$, aMCI and mild AD, it is interesting to note the disparity in CSDD scores of subjects with 1 -aMCI (with mean scores $>6$, suggesting the possibility of a depressive state) compared to the other MCI subtypes. In a recent study, Lu et al. [35] have reported that the presence of depression is predictive of progression of aMCI to $\mathrm{AD}$, and donepezil treatment may modulate this increased risk. Edwards et al. [36] similarly noted the association of depressive symptoms with aMCI and an increased risk of progression to dementia in subjects with greater neuropsychiatric symptoms. It is highly likely that the affective symptoms demonstrated in these vulnerable MCI subjects reflect the underlying neurodegenerative process [37], and their presence should warrant closer inspection and follow-up.

Strengths of the current study include the comprehensive assessment of subjects with locally validated cognitive instruments, and the use of consensus-derived clinical classification for aMCI and AD subjects. An important limitation of the study was that most of the ND subjects in our cohort have subjective memory complaints and may not be representative of normal elderly subjects in the general population, even though such an approach may be useful for clinicians in the memory clinic setting. Previous works have highlighted that the presence of subjective memory complaints is itself a risk factor for subsequent development of dementia [38], and the ability to clinically differentiate this at-risk group from aMCI subjects provides further credence to the concept of a spectrum of deficits in subjects with subtle memory complaints which warrants further exploration. Finally, the psychometric battery employed did not have a specific executive function domain which might correlate with function on iADL assessment, although this is partially addressed by the inclusion of the category verbal fluency (animal naming) in the test, which requires a significant degree of executive functioning.

In conclusion, findings of the current study suggest that further subtyping of aMCI subjects was possible based on neuropsychological and functional performance, which could be represented by their CDR-SB scores. Accurate clinical characterization of aMCI is crucial for advancing our knowledge on disease progression and the development of suitable biomarkers for Alzheimer's pathology. The utility of such a clinical classification system for sample enrichment in MCI therapeutic trials may be explored in future studies.

\section{Acknowledgments}

The authors would like to thank all the members of the Cognition and Memory Disorders Service for their ideas on the paper, Dr. Cindy Yeo for her technical support of the memory clinic database and Dr. Sitoh Yih Yian for his advice on neuroimaging analyses.

\section{Conflicts of Interest}

All authors confirm that there was no conflict of interest and that they have not received any payment for research, consultantships or speakers' forum, and do not have any company holdings or patents in connection with this study. 


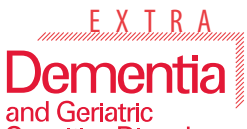

and Geriatric

Cognitive Disorders
Dement Geriatr Cogn Disord Extra 2011;1:113-123

\begin{tabular}{l|l}
\hline DOI: 10.1159/000327519 & ( 2011 S. Karger AG, Basel
\end{tabular}

Published online: April 27, 2011

Chan et al.: Disease Spectrum of Amnestic MCI

\section{References}

1 Petersen RC, Smith GE, Waring SC, Ivnik RJ, Tangalos EG: Mild cognitive impairment: clinical characterization and outcome. Arch Neurol 1999;56:303-308.

2 Winblad B, Palmer K, Kivipelto M, Jelic V, Fratiglioni L, Wahlund LO, Nordberg A, Backman L, Albert M, Almkvist O, Arai H, Basun H, Blennow K, DeLeon M, DeCarli C, Erkinjuntti T, Gaicobini E, Graff C, Hardy J, Jack C, Norm A, Ritchie K, Van Duijn CV, Visser P, Petersen RC: Mild cognitive impairment - beyond controversies, towards a consensus: report of the International Working Group on Mild Cognitive Impairment. J Intern Med 2004;256:240-246.

-3 Fleisher AS, Sowell BB, Taylor C, Gamst AC, Petersen RC, Thal LJ: Clinical predictors of progression to Alzheimer disease in amnestic mild cognitive impairment. Neurology 2007;68:1588-1595.

-4 Dickerson BC, Sperling RA, Hyman BT, Albert MS: Clinical prediction of Alzheimer disease dementia across the spectrum of mild cognitive impairment. Arch Gen Psychiatry 2007;64:1443-1450.

-5 Cummings JL, Doody R, Clark C: Disease-modifying therapies for Alzheimer disease: challenges to early intervention. Neurology 2007;69:1622-1634.

-6 Gauthier S, Reisberg B, Zaudig M, Petersen RC, Ritchie K, Belleville S, Brodaty H, Bennett D, Chertkow H, Cummings JL, DeLeon M, Feldman H, Ganguli M, Hampel H, Scheltens P, Tierney MC, Whitehouse P, Winblad B : Mild cognitive impairment. Lancet 2006;367:1262-1270.

-7 Mitchell J, Arnold R, Dawson K, Nestor PJ, Hodges JR: Outcome in subgroups of mild cognitive impairment (MCI) is highly predictable using a simple algorithm. J Neurol 2009;256:1500-1509.

8 Petersen RC, Thomas RG, Grundman M, Bennett D, Doody R, Ferris S, Galasko D, Jin S, Kaye J, Levey A, Pfeiffer E, Sano M, van Dyck CH, Thal LJ: Vitamin E and donepezil for the treatment of mild cognitive impairment. N Engl J Med 2005;352:2379-2388.

-9 Winblad B, Gauthier S, Scinto L, Feldman H, Wilcock GK, Truyen L, Mayorga AJ, Wang D, Brashear HR, Nye JS: Safety and efficacy of galantamine in subjects with mild cognitive impairment. Neurology 2008;70:2024-2035.

-10 Thal LJ, Ferris SH Thal LJ, Ferris SH, Kirby L, Block GA, Lines CR, Yuen E, Assaid C, Nessly ML, Norman BA, Baranak CC, Reines SA, Rofecoxib Protocol 078 Study Group: A randomized, doubleblind study of rofexocib in patients with mild cognitive impairment. Neuropsychopharmacology 2005;30:1204-1215.

-11 Geslani D, Tierney MC, Hermann N, Szalai JP: Mild cognitive impairment: an operational definition and its conversion rate to Alzheimer's disease. Dement Geriatr Cogn Disord 2005;19:383-389.

-12 Kramer JH, Nelson A, Johnson JK, Yaffe K, Glenn S, Rosen HJ, Miller BL: Multiple cognitive deficits in amnestic mild cognitive impairment. Dement Geriatr Cogn Disord 2006;22:306-311.

13 Morris JC: The Clinical Dementia Rating (CDR): current version and scoring rules. Neurology 1993; 43:2412-4.

14 Chong MS, Sahadevan S: An evidence-based approach to the diagnosis of dementia. Ann Acad Med Singapore 2003;32:740-748.

-15 Sahadevan S, Lim PP, Tan NJ, Chan SP: Diagnostic performance of two mental status tests in the older Chinese: influence of education and age on cut-off values. Int J Geriatr Psychiatry 2000;15: 234-241.

-16 Alexopoulos GA, Abrams RC, Young RC, Shamoian CA: Cornell Scale for Depression in Dementia. Biol Psychiatry 1988;23:271-284.

$\checkmark 17$ Lam CK, Lim PP, Low BL, Ng LL, Chiam PC, Sahadevan S: Depression in dementia: a comparative and validation study of four brief scales in the elderly Chinese. Int J Geriatr Psychiatry 2004;19:422428.

-18 Lim WS, Chin JJ, Lam CK, Lim PPJ, Sahadevan S: Clinical dementia rating: experience of a multiracial Asian population. Alzheimer Dis Assoc Disord 2005;19:135-142.

-19 Lawton MP, Brody EM: Assessment of older people: self-maintaining and instrumental activities of daily living. Gerontologist 1969;9:179-186.

-20 Barberger-Gateau P, Gagnon M, Letenneur L, Sauvel C, Dartigues JF: Instrumental activities of daily living as a screening tool for cognitive impairment and dementia in elderly community dwellers. J Am Geriatr Soc 1992;40:1129-1134.

-21 Sahadevan S, Lim JP, Tan NJ, Chan SP: Psychometric identification of early Alzheimer disease in an elderly Chinese population with differing educational levels. Alzheimer Dis Assoc Disord 2002:16: $65-72$. 
22 Scheltens P, Leys D, Barkhof F, et al: Atrophy of medial temporal lobes on MRI in 'probable' Alzheimer's disease and normal ageing: diagnostic value and neuropsychological correlates. J Neurol Neurosurg Psychiatry 1992;55:967-972.

-23 Wahlund LO, Barkhof F, Fazekas F, Bronge L, Augustin M, Sjogren M, Wallin A, Ader H, Leys D, Pantoni L, Pasquier F, Erkinjuntti T, Scheltens P: A new rating scale for age-related white matter changes applicable to MRI and CT. Stroke 2001;32:1318-1322.

-24 McKhann G, Drachman D, Folstein M, Katzman R, Price D, Stadlan EM: Clinical diagnosis of Alzheimer's Disease: report of the NINCDS-ADRDA Work Group under the auspices of the Department of Health and Human Services Task Force on Alzheimer's Disease. Neurology 1984;34:939944.

-25 Petersen RC: Mild cognitive impairment as a diagnostic entity. J Intern Med 2004;256:183-194.

-26 Busse A, Hensel A, Guhne U, Angermeyer MC, Riedel-Heller SG: Mild cognitive impairment: longterm course of four clinical subtypes. Neurology 2006;67:2176-2185.

-27 Vemuri P, Wiste HJ, Weigand SD, Shaw LM, Trojanowski JQ, Weiner MW, Knopman DS, Petersen RC, Jack CR: MRI and CSF biomarkers in normal, MCI, and AD subjects: predicting future clinical change. Neurology 2009;78:294-301.

-28 Mattsson N, Zetterberg H, Hansson O, Andreasen N, Parnetti L, Jonsson M, Herukka SK, van der Flier WM, Blankenstein MA, Ewers M, Rich K, Kaiser E, Verbeek E, Tsolaki M, Mulugeta E, Rosen E, Aarsland D, Visser PJ, Schroder J, Marcusson J, deLeon M, Hampel H, Scheltens P, Pirttila T, Wallin A, Jonhagen ME, Minthon L, Winblad B, Blennow K: CSF biomarkers and incipient Alzheimer disease in patients with mild cognitive impairment. JAMA 2009;302:385-393.

-29 Storandt M, Grant EA, Miller JP, Morris JC: Longitudinal course and neuropathologic outcomes in original vs. revised MCI and in pre-MCI. Neurology 2006;67:467-473.

-30 Daly E, Zaitchik D, Copeland M, Schmahmann J, Gunther J, Albert M: Predicting conversion to Alzheimer disease using standardized clinical information. Arch Neurol 2000;57:675-680.

- 31 Saxton J, Snitz BE, Lopez OL, Ives DG, Dunn LO, Fitzpatrick A, Carlson MC, Dekosky ST: Functional and cognitive criteria produce different rates of mild cognitive impairment and conversion to dementia. J Neurol Neurosurg Psychiatry 2009;80:737-743.

-32 Farias ST, Mungas D, Reed BR, Reed BP, Harvey D, Cahn-Weiner D, DeCarli C: MCI is associated with deficits in everyday functioning. Alzheimer Dis Assoc Disord 2006;20:217-223.

- 33 Mariani E, Monastero R, Ercolani S, Rinaldi P, Mangialasche F, Costanzi E, Vitale DF, Senin U, Mecocci P: Influence of comorbidity and cognitive status on instrumental activities of daily living in amnestic mild cognitive impairment: results from the ReGAI project. Int J Geriatr Psychiatry 2008: 23:523-530.

-34 Wadley VG, Crowe M, Marsiske M, Cook SE, Unverzagt FW, Rosenberg AL, Rexroth D: Changes in everyday function in individuals with psychometrically defined mild cognitive impairment in the Advanced Cognitive Training for Independent and Vital Elderly Study. J Am Geriatr Soc 2007;55: 1192-1198.

- 35 Lu PH, Edland SD, Teng E, Tingus K, Petersen RC, Cummings JL: Donepezil delays progression to AD in MCI subjects with depressive symptoms. Neurology 2009;72:2115-2121.

-36 Edwards ER, Spira AP, Barnes DE, Yaffe K: Neuropsychiatric symptoms in mild cognitive impairment: differences by subtype and progression to dementia. Int J Geriatr Psychiatry 2009;24:716-722.

-37 Rozzini L, Chilovi BV, Conti M, Delrio I, Borroni B, Trabucchi M, Padovani A: Neuropsychiatric symptoms in amnestic mild cognitive impairment. Dement Geriatr Cogn Disord 2008;25:32-36.

- 38 Gallassi R, Bisulli A, Oppi F, Poda R, Felice CD: Subjective cognitive complaints, neuropsychological performance, affective and behavioural symptoms in non-demented patients. Int J Geriatr Psychiatry 2008;23:95-101. 